\title{
Worldwide Occurrence of Beijing/W Strains of Mycobacterium tuberculosis: A Systematic Review
}

\author{
Judith R. Glynn, ${ }^{*}$ Jennifer Whiteley, ${ }^{*}$ Pablo J. Bifani, $†$ Kristin Kremer,‡ \\ and Dick van Soolingen $\ddagger$
}

\begin{abstract}
Strains of the Beijing/W genotype family of Mycobacterium tuberculosis have caused large outbreaks of tuberculosis, sometimes involving multidrug resistance. This genetically highly conserved family of $M$. tuberculosis strains predominates in some geographic areas. We have conducted a systematic review of the published reports on these strains to determine their worldwide distribution, spread, and association with drug resistance. Sixteen studies reported prevalence of Beijing strains defined by spoligotyping; another 10 used other definitions. Beijing strains were most prevalent in Asia but were found worldwide. Associations with drug resistance varied: in New York, Cuba, Estonia, and Vietnam, Beijing strains were strongly associated with drug resistance, but elsewhere the association was weak or absent. Although few reports have measured trends in prevalence, the ubiquity of the Beijing strains and their frequent association with outbreaks and drug resistance underline their importance.
\end{abstract}

I $\mathrm{n}$ the early 1990s, a multidrug-resistant Mycobacterium tuberculosis strain was identified in New York (1). This strain, designated "W," which was associated with large institutional outbreaks of tuberculosis (TB) and many deaths, was later identified in other parts of the United States $(2,3)$. In 1995, a large proportion of the M. tuberculosis strains in the Beijing area of China was reported to have mutually highly similar multi-banded IS6110 restriction fragment-length polymorphism (RFLP) patterns; these "Beijing" strains were also present in many other populations (4).

The New York City multidrug-resistant "W" strain was, in the second half of the 1990s, recognized as a member of the "Beijing" genotype family of $M$. tuberculosis strains (5-7). The W strain is recognized by a specific IS6110 fingerprint pattern, by multiplex polymerase chain reaction (PCR) targeted at specific insertions, or both $(2,3)$. W family strains have IS6110 patterns closely related to that of $\mathrm{W}$, although the degree of similarity in different studies has not always been specified. Beijing strains, including the $\mathrm{W}$ variants, have an insertion of IS 6110 in the genomic dnaA-dnaN locus $(5,7)$. All $\mathrm{W}$ family strains have a characteristic spoligotype that is shared with the whole Beijing family of strains and seems to be specific for this family $(4,8,9)$. Spoligotyping is based on DNA polymorphism in the direct repeat region, and "Beijing" spoligotypes only contain spacers $35-43$.

The combination of a widespread family of strains and, in some situations, the association with multidrug resistance has led to concern that these strains may be spreading and may

*London School of Hygiene and Tropical Medicine, London, UK; †Institut Pasteur de Lille, France; and $\ddagger$ National Institute of Public Health and the Environment (RIVM), Bilthoven, the Netherlands have a predilection for acquiring drug resistance. Many recent studies have recorded "Beijing-like" or "W-like" strains. We have conducted a systematic review of published reports to assess how widespread the family of strains is, whether there is any evidence that it is spreading, and whether it is associated with drug resistance.

\section{Methods}

Relevant studies were identified through computerized searches of Medline (January 1, 1990-November 1, 2001) and PubMed (January 1, 2000-November 1, 2001), manually searching key journals, searching the Internet, and crosschecking references with collections of articles on Beijing strains compiled by researchers in the field. The computerized searches used both thesaurus and free-text terms to search for tuberculosis and any of the following: molecular epidemiology, DNA fingerprinting, DNA fingerprint*, typing, type, types, restriction fragment length polymorphism, RFLP, spoligotyping, spoligotyp*, strain, and strains. The International Journal of Tuberculosis and Lung Disease, its predecessor Tuberculosis and Lung Disease, and the Journal of Clinical Microbiology were searched manually back to January 1990. A request for relevant articles was sent to all 32 participants in the European Union Concerted Action project on New Generation Genetic Markers and Techniques for the Epidemiology and Control of Tuberculosis. An Internet search, using Google, used the term "Beijing strain tuberculosis." The reference lists of all included articles were searched for additional relevant studies.

Articles were included if they contained information allowing estimation of the proportion of TB patients included with the Beijing or W strains. Articles were excluded if they 
were limited to a particular outbreak, if they included only drug-resistant strains, or if $<30 \mathrm{~TB}$ patients were included. Identified articles were subdivided into those that used spoligotyping to identify Beijing family strains and those that used other methods. Where spoligotypes were shown, estimates based on the spoligotype were used rather than any estimate given in the papers, using the proportion with spacers 35-43. Studies identifying only W strains or other W-like strains with a single IS6110 fingerprint pattern will underestimate the prevalence of Beijing strains, since they identify only part of the family of strains. The method of patient selection was recorded when stated. In all studies, any evidence of changes over time or by age group or of any association between strain type and drug resistance was recorded.

\section{Results}

Five thousand nineteen articles were selected from the initial search of Medline and PubMed. The titles and abstracts of these articles were scanned for relevant information, and 4,909 articles were rejected, leaving 110 articles for full text review. No further articles were identified by manual searching, but one recently published article was identified in the article collections that had not yet been indexed in the databases (10). One additional article was identified from reference list checking that was published in a Vietnamese journal not indexed by Medline, EMBASE, or Web of Science, and we have been unable to locate it. Another article was found from an Internet search, in an electronic journal (11). Of the 112 articles reviewed in full, 26 fulfilled the inclusion criteria of this review, including 16 that gave results based on spoligotyping and several that reported results from more than one area (Tables 1,2; Figure). Studies that described patients who were apparently included in other reports have been excluded $(31,32)$.

The Beijing strain was most common in the Beijing area of China, accounting for $92 \%$ of strains $(4,12)$. The strain was common in all the Asian studies $(4,8,12-15,23-25)$ and also in Houston, Texas (25\%), and Estonia (29\%) $(18,20)$. Some examples of the Beijing family were seen in almost all the populations studied (Tables 1 and 2).

Two studies looked at trends over time (Table 1). In China, the proportion of TB due to Beijing family strains in stored specimens going back to the 1950 s was similar to the proportion among more recent specimens (12). In Gran Canaria, a dramatic increase was seen from 1992 to 1996 , traced to an outbreak originating from a noncompliant patient with laryngeal TB (19). In studies over a short period, variations with age can be studied as a proxy for time trends. In Vietnam, among new cases of TB, the proportion due to Beijing strains was $71 \%$ in those $<25$ years of age, decreasing to $41 \%$ in those $\geq 55$ years $(\mathrm{p}<0.001$, chi square test for trend) (14). In Bangkok, little difference was seen with age in two studies $(15,24)$. In Hong Kong (13), Jakarta, Indonesia (8), and Estonia (18), there was no association between age and disease due to the Beijing strain. In New Jersey, among those with tubercu- losis due to W-like strains, $70 \%$ of patients were $<50$ years old, compared with $63 \%$ of those with other strains $(p=0.2)(9)$. In Gran Canaria, the median age of cases with the Beijing strain was similar to that of all cases (19). No other studies have presented results by age.

Several studies reported associations with drug resistance (Table 3). Some studies found high rates of drug resistance among Beijing strains, but others found no difference in drug resistance profiles between Beijing and the other local strains.

An association between the successful spread of Beijing strains and BCG vaccination has been suggested (4). In Jakarta, Indonesia (8), $26 \%$ of those with Beijing strains and $23 \%$ of other patients had a BCG scar. In Vietnam, although a higher proportion of those with Beijing strains than with other strains had a BCG scar, this association was no longer apparent after the data were adjusted for age (14).

\section{Discussion}

This review has confirmed the ubiquity of the Beijing family of strains. Only a few of the smaller studies (in Martinique and French Guiana) found no examples, and the proportion of TB due to Beijing strains in several Asian studies was $>50 \%$. However, studies could only be included in the review if they mentioned the Beijing strain or strain $\mathrm{W}$ or presented data showing spoligotypes. Some of the excluded studies may have found Beijing strains but not reported them as such $(33,34)$. Others may have looked for Beijing strains but not reported negative findings. The only articles identified that reported not finding Beijing strains were studies including more than one study site. It is not known how unusual it is for a genotype family of M. tuberculosis to be as widespread as this. Comparable data are not available for other strains, although they are beginning to be gathered, and some other strains have also been found in several distinct settings (35).

In many studies, the true proportion of TB attributable to the Beijing family of strains is hard to assess. Difficulties arise due to the variable strain definitions used and the way patients were selected for inclusion. Spoligotyping seems to be both sensitive and specific for the Beijing family and is also easily compared between studies (6). Although IS6110 fingerprinting can also be used to detect this genotype family, with results that correlate closely with the spoligotypes, most published studies have used narrow definitions, based on a single strain or a few closely related strains defined by IS6110 fingerprinting; such studies are thus likely to underestimate the prevalence of Beijing strains. Studies including drug resistance in the definition (2) and those that appear to have defined the strains after grouping by drug resistance (26) may also underestimate the prevalence.

Some of the studies (those in the Netherlands, New Jersey, Houston, Texas, Gran Canaria, and French Guiana and the Caribbean islands) included information on all TB patients in the population and thus provide reliable estimates of prevalence. Others were less representative, and many did not state how the patients were selected (Table 1 and 2). Studies that 
Table 1. Prevalence of Beijing family strains in studies that have used spoligotyping ${ }^{a}$

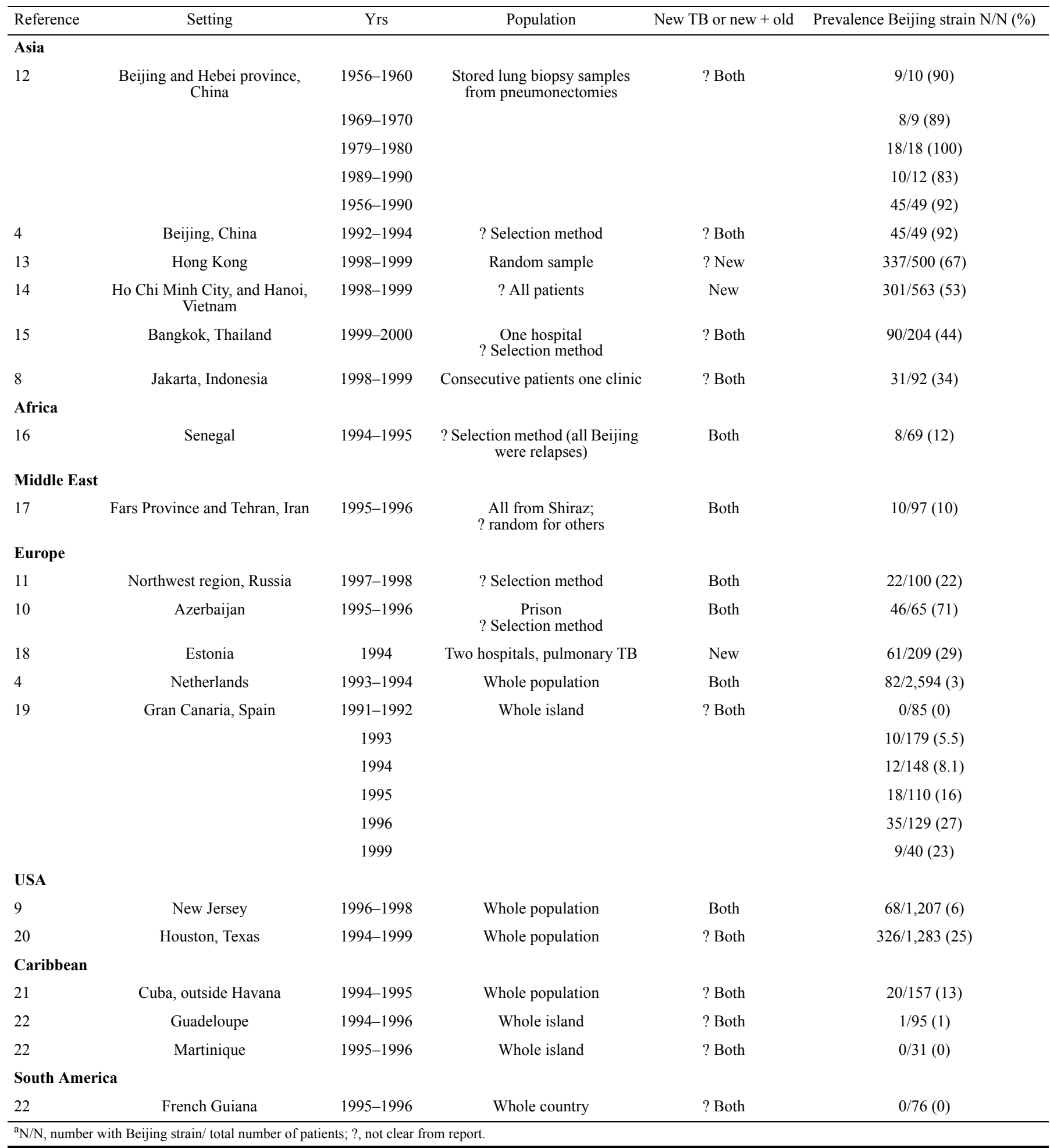

included patients from particular hospitals may be representative of an area, but referral hospitals may be biased if they accept a high proportion of drug-resistant or complex cases. Similarly, convenience samples may not be representative of the community of TB patients, particularly if the samples were kept because they were interesting in some way (e.g., drug resistant or from epidemiologically related cases). TB patients in prison (10) may not have the same strains as those in the community. Some studies included only new patients, and others included both new patients and recurrent cases. This distinction, which was often not clear in the reports, could influence the results if relapse rates differ between strains. 
Table 2. Prevalence of Beijing and W-like strains in studies not based on spoligotyping ${ }^{a}$

\begin{tabular}{|c|c|c|c|c|c|c|}
\hline Reference & Setting & Yrs & Population & $\begin{array}{l}\text { New TB or } \\
\text { new }+ \text { old }\end{array}$ & Typing methods and definitions used & $\begin{array}{l}\text { Prevalence of } \\
\text { Beijing strain } \\
\text { N/N (\%) }\end{array}$ \\
\hline \multicolumn{7}{|l|}{ Asia } \\
\hline 23 & Philippines & $?$ & No information given & $?$ & $\mathrm{RFLP}+3.6 \mathrm{~kb} P v u$ II fragment & $34 / 34(100)$ \\
\hline 23 & Thailand & ? & No information given & $?$ & RFLP $+3.6 \mathrm{~kb} P v u$ II fragment & $31 / 49(63)$ \\
\hline 24 & $\begin{array}{l}\text { Bangkok } \\
\text { Nonthaburi, Thailand }\end{array}$ & $1994-1995$ & $\begin{array}{l}\text { Patients from } 3 \text { hospitals ? how } \\
\text { selected. Half extrapulmonary }\end{array}$ & ? Both & $\begin{array}{l}\text { RFLP }+ \text { comparison } \\
\text { with Dutch database }\end{array}$ & $80 / 211(37)$ \\
\hline 23 & Malaysia & $?$ & No information given & $?$ & RFLP $+3.6 \mathrm{~kb} P v u$ II fragment & $17 / 48(35)$ \\
\hline 26 & $\begin{array}{l}\text { Cape Town, South } \\
\text { Africa }\end{array}$ & 1993-1997 & Whole population & Both & $\begin{array}{l}\text { RFLP "strain U", (W-like) } \\
\text { Two closely related patterns only }\end{array}$ & $17 / 650(2.6)$ \\
\hline \multicolumn{7}{|l|}{ USA } \\
\hline 27 & New York City & 1992-1994 & Patients from 5 hospitals & ? Both & RFLP, strain W only & $6 / 302(2.0)$ \\
\hline 3 & New York City & 1990-1995 & ? selection method & ? Both & RFLP, "W-like" & 273/1,953 (14) \\
\hline 28 & Central Los Angeles & 1994-1996 & Consecutive patients & ? Both & RFLP, strain 210 (W-related) & $43 / 162(27)$ \\
\hline 29 & California & $1992-1995$ & All cases from specific locations & ? Both & RFLP, strain 210 (W-related) & $39 / 522(7)$ \\
\hline 29 & Texas & 1993-1995 & All cases from specific locations & ? Both & RFLP, strain 210 (W-related) & $16 / 546(3)$ \\
\hline 29 & Colorado & 1989-1994 & All cases from specific locations & ? Both & RFLP, strain 210 (W-related) & $2 / 256(0.8)$ \\
\hline
\end{tabular}

In many studies, some culture-positive specimens are not typed because they are nonviable. IS6110 RFLP typing relies on large quantities of DNA and hence on viable strains, and theoretically some genotypes may survive better than others in vitro. Spoligotyping is PCR-based so does not require viable isolates, but it is sometimes used only as a secondary method in specimens that have already been typed by IS6110 RFLP.

Associations with drug resistance were variable (Table 3): of the 12 studies with data available, only 4 found statistically significant increases in the proportions of drug resistance among those with Beijing strains. Of the Asian studies, only one found a statistically significant increase in drug resistance in Beijing strains (14), and in Hong Kong the Beijing strains were less likely than the others to be isoniazid resistant (13). In contrast, Beijing strains were strongly associated with drug resistance in New York, Cuba, and Estonia $(3,18,21)$. In New
York, the spread of the W strain, which was mainly nosocomial and institutional, has been attributed in part to drug resistance. Once a strain has become multidrug resistant, treatment is more complicated so patients may remain infectious for a longer period. Whether the Beijing family has a particularly high probability of acquiring drug resistance is not known but is suggested by the fact that these associations with the same strain family have been found in widely distributed areas.

The published studies provided little direct evidence that the Beijing strain has been increasing. Of the two studies that included time trends, one found no increase in a population with a very high prevalence for many decades (12), and in the other the increase may be attributable to the characteristics of the index patient in the outbreak $(19,36)$. In Vietnam, the proportion of new TB patients with the Beijing strain decreased with age, suggesting an increase in Beijing strains in the com- 
Table 3. Association between Beijing family strains of Mycobacterium tuberculosis and drug resistance ${ }^{a}$

\begin{tabular}{|c|c|c|c|c|c|c|c|c|c|c|c|c|}
\hline \multirow[b]{3}{*}{ Reference } & \multirow[b]{3}{*}{ Place, yr } & & & \multicolumn{8}{|c|}{$\%$ Drug resistance } & \multirow{3}{*}{$\begin{array}{l}\text { Comparison of Beijing } \\
\text { vs. non-Beijing by drug } \\
\text { RR } 95 \% \mathrm{CI}^{\mathrm{b}}\end{array}$} \\
\hline & & \multicolumn{2}{|c|}{ Strain } & \multicolumn{2}{|c|}{ Any } & \multicolumn{2}{|c|}{$\mathrm{I}$} & \multicolumn{2}{|c|}{$S$} & \multicolumn{2}{|c|}{ MDR } & \\
\hline & & Beijing & $\begin{array}{c}\text { Non- } \\
\text { Beijing }\end{array}$ & Beijing & $\begin{array}{c}\text { Non- } \\
\text { Beijing }\end{array}$ & Beijing & $\begin{array}{c}\text { Non- } \\
\text { Beijing }\end{array}$ & Beijing & $\begin{array}{c}\text { Non- } \\
\text { Beijing }\end{array}$ & Beijing & $\begin{array}{c}\text { Non- } \\
\text { Beijing }\end{array}$ & \\
\hline 13 & $\begin{array}{l}\text { Hong Kong, } \\
1998-1999\end{array}$ & 310 & 181 & & & 6 & 12 & 10 & 13 & & & $\begin{array}{l}\text { I } 0.54(0.30 \text { to } 0.97) \\
\text { S } 0.76(0.46 \text { to } 1.3)\end{array}$ \\
\hline 14 & $\begin{array}{l}\text { Ho Chi } \\
\text { Minh City, } \\
\text { 1998-1999 }\end{array}$ & 264 & 235 & & & 28 & 19 & 42 & 19 & 3 & 2 & $\begin{array}{c}\text { I } 1.5(1.1 \text { to } 2.0) \\
\text { S } 2.2(1.6 \text { to } 3.0) \\
\text { MDR } 1.4(0.47 \text { to } 4.3)\end{array}$ \\
\hline 15 & $\begin{array}{l}\text { Bangkok, } \\
\text { 1999-2000 }\end{array}$ & 90 & 114 & & & & & & & & & No assoc \\
\hline 8 & $\begin{array}{l}\text { Jakarta, } \\
\text { 1998-1999 }\end{array}$ & 27 & 56 & 41 & 25 & 37 & 20 & 15 & 5 & & & $\begin{array}{l}\text { Any } 1.6(0.86 \text { to } 3.1) \\
\text { I } 1.9(0.92 \text { to } 3.9) \\
\text { S } 2.8(0.67 \text { to } 11.5)\end{array}$ \\
\hline 16 & $\begin{array}{l}\text { Senegal, } \\
\text { 1994-1995 }\end{array}$ & 8 & 61 & & & & & & & & & No assoc \\
\hline 18 & $\begin{array}{l}\text { Estonia, } \\
1994\end{array}$ & 61 & 148 & 70 & 14 & & & & & 34 & 2 & $\begin{array}{l}\text { Any } 5.0(3.2 \text { to } 7.6) \\
\text { MDR } 17.0(5.3 \text { to } 54.9)\end{array}$ \\
\hline 19 & $\begin{array}{c}\text { Gran } \\
\text { Canaria, } \\
\text { 1991-1996 }\end{array}$ & 75 & 576 & 0 & $?$ & & & & & & & \\
\hline 3 & $\begin{array}{l}\text { New York, } \\
1990-1995\end{array}$ & $\begin{array}{l}273 \\
\text { (W- } \\
\text { like) }\end{array}$ & $\begin{array}{l}1,680 \\
\text { (not W } \\
\text { like) }\end{array}$ & & & & & & & $93^{\mathrm{c}}$ & $? 0$ & $\mathrm{p}<0.001$ \\
\hline $21^{d}$ & $\begin{array}{c}\text { Cuba, } \\
1994-1995\end{array}$ & 20 & 137 & $55-65$ & $4-5$ & $55-60$ & 4 & $0-10$ & $0.7-2$ & 0 & 0.7 & $\begin{array}{l}\text { Any } 10.8(4.7 \text { to } 24.5) \\
\text { I } 15.1(5.8 \text { to } 38.9)\end{array}$ \\
\hline
\end{tabular}

munities studied (14). No association with age was found anywhere else $(8,9,13,15,18,19,24)$, including the two other studies restricted to new patients $(13,18)$.

On the other hand, the ubiquity of the Beijing strain and its frequent appearance in outbreaks, particularly of drug-resistant TB, suggest that it may have the potential to spread. In Estonia, although there was no association between Beijing strains and age, TB and particularly multidrug-resistant (MDR) TB have been increasing, and most MDR TB was found to be due to Beijing strains (18). The limited amount of information available from most areas of the world and the possible biases in many of the studies make definite conclusions about the extent of spread and associations with drug resistance impossible. Through the European Concerted Action on New Generation Genetic Markers and Techniques for the Epidemiology and Control of Tuberculosis, a standard definition of the Beijing genotype is being finalized, by comparisons of large collections of strains typed with spoligotyping, IS6110 RFLP, and Region A RFLP, which visualizes insertion of IS6110 in the genomic dnaA-dnaN locus (ms. in preparation). Studies are planned to reanalyze available data worldwide by using standard definitions and approaches.

Further studies are also needed to include more areas in an unbiased way, to study historical specimens if possible, and to investigate the virulence (8) and transmissibility of this potentially important family of $M$. tuberculosis strains. The question to be answered is if and to what extent Beijing genotype strains have selective advantages over other $M$. tuberculosis genotypes in the ability to gain resistance and to interact with the host immune defense system. If Beijing genotype strains represent a higher level of evolutionary development of $M$. tuberculosis being selected for as a result of the introduction of tuberculostatics, which inhibit the growth of M. tuberculosis, then consequences for the treatment of tuberculosis will be serious. 


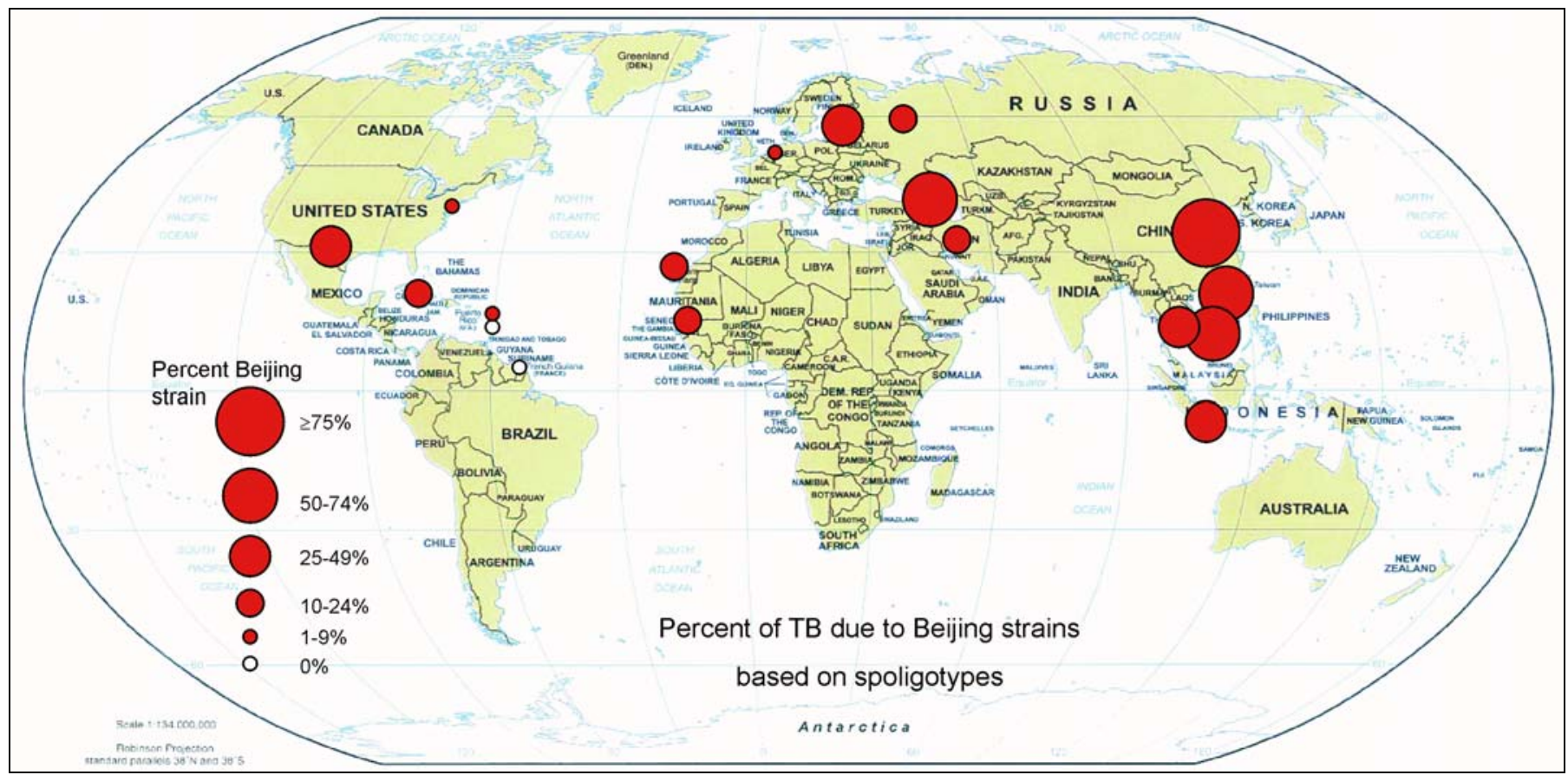

Figure. Percentage of tuberculosis due to Beijing strains. Data from studies based on spoligotyping (Table 1).

\section{Acknowledgments} draft.

We thank Martien Borgdorff for helpful comments on an earlier

This paper was written as part of the EU Concerted Action project QLK2-CT-2000-00630. JRG is partially funded by the Department for International Development, United Kingdom.

Dr. Glynn is a senior lecturer in epidemiology at the London School of Hygiene and Tropical Medicine, London, United Kingdom. Her research interests include tuberculosis, HIV, and molecular epidemiology.

\section{References}

1. Hewlett D Jr, Franchini D, Horn D, Alfalla C, Yap R, Di Pietro D, et al. Outbreak of multidrug-resistant tuberculosis at a hospital-New York City, 1991. MMWR Morb Mortal Wkly Rep 1993;42:427-33.

2. Agerton TB, Valway SE, Blinkhorn RJ, Shilkret KL, Reves R, Schluter $\mathrm{W}$, et al. Spread of strain W, a highly drug-resistant strain of Mycobacterium tuberculosis, across the United States. Clin Infect Dis 1999;29:8592.

3. Bifani PJ, Plikaytis BB, Kapur V, Stockbauer K, Pan X, Lutfey ML, et al. Origin and interstate spread of a New York City multidrug-resistant Mycobacterium tuberculosis clone family. JAMA 1996;275:452-7.

4. Van Soolingen D, Qian L, de Haas PEW, Douglas JT, Traore H, Portaels F, et al. Predominance of a single genotype of Mycobacterium tuberculosis in countries of East Asia. J Clin Microbiol 1995;33:3234-8.

5. Kurepina NE, Sreevatsan S, Plikaytis BB, Bifani PJ, Connell ND, Donnelly RJ, et al. Characterization of the phylogenetic distribution and chromosomal insertion sites of five IS6110 elements in Mycobacterium tuberculosis: non-random integration in the dnaA-dnaN region. Tuber Lung Dis 1998;79:31-42.

6. Van Soolingen D. Molecular epidemiology of tuberculosis and other mycobacterial infections: main methodologies and achievements. J Intern Med 2001;249:1-26.
7. Bifani PJ, Mathema B, Kurepina NE, Kreiswirth BN. Global dissemination of the Mycobacterium tuberculosis W-Beijing family strains. Trends in Microbiology 2002:10;45-52.

8. van Crevel R, Nelwan RHH, de Lenne W, Veeraragu Y, van der Zanden AG, Amin Z, et al. Mycobacterium tuberculosis Beijing genotype strains associated with febrile response to treatment. Emerg Infect Dis 2001;7:1-4.

9. Bifani PJ, Mathema B, Liu Z, Moghazeh S, Shopsin B, Tempalski B, et al. Identification of a $\mathrm{W}$ variant outbreak of Mycobacterium tuberculosis via population-based molecular epidemiology. JAMA 1999;282:2321-7.

10. Pfyffer GE, Strassle A, van Gorkom T, Portaels F, Rigouts L, Mathieu C, et al. Multidrug-resistant tuberculosis in prison inmates, Azerbaijan. Emerg Infect Dis 2001;7:855-61.

11. Narvskaya O, Mokrousov I, Limeschenko E, Otten T, Steklova L, Graschenkova $\mathrm{O}$, et al. Molecular characterization of Mycobacterium tuberculosis strains from the northwest region of Russia. EpiNorth 2000;1. Available from: URL: http://www.epinorth.org/english/2000/2/ 002c.shtml (accessed 10.8.01)

12. Qian L, Van Embden JD, Van Der Zanden AG, Weltevreden EF, Duanmu $\mathrm{H}$, Douglas JT. Retrospective analysis of the Beijing family of Mycobacterium tuberculosis in preserved lung tissues. J Clin Microbiol 1999;37:471-4.

13. Chan MY, Borgdorff M, Yip CW, de Haas PE, Wong WS, Kam KM, et al. Seventy percent of the Mycobacterium tuberculosis isolates in Hong Kong represent the Beijing genotype. Epidemiol Infect 2001;127:169-71.

14. Anh DD, Borgdorff M, Van LN, Lan NTN, van Gorkom T, Kremer K, et al. Mycobacterium tuberculosis Beijing genotype emerging in Vietnam. Emerg Infect Dis 2000;6:302-5.

15. Prodinger WM, Bunyaratvej P, Prachaktam R, Pavlic M. Mycobacterium tuberculosis isolates of Beijing genotype in Thailand. Emerg Infect Dis 2001;7:483-4.

16. Niang MN, de la Salmoniere YG, Samb A, Hane AA, Cisse MF, Gicquel $\mathrm{B}$, et al. Characterization of M. tuberculosis strains from west African patients by spoligotyping. Microbes Infect 1999;1:1189-92.

17. Doroudchi M, Kremer K, Basiri EA, Kadivar MR, Van Soolingen D, Ghaderi AA. IS6110-RFLP and spoligotyping of Mycobacterium tuberculosis isolates in Iran. Scand J Infect Dis 2000;32:663-8. 
18. Kruuner A, Hoffner SE, Sillastu H, Danilovits M, Levina K, Svenson SB, et al. Spread of drug-resistant pulmonary tuberculosis in Estonia. J Clin Microbiol 2001;39:3339-45.

19. Caminero JA, Pena MJ, Campos-Herrero MI, Rodriguez JC, Garcia I, Cabrera P, et al. Epidemiological evidence of the spread of a Mycobacterium tuberculosis strain of the Beijing genotype on Gran Canaria Island. Am J Respir Crit Care Med 2001;164:1165-70.

20. Soini H, Pan X, Amin A, Graviss EA, Siddiqui A, Musser JM. Characterization of Mycobacterium tuberculosis isolates from patients in Houston, Texas, by spoligotyping. J Clin Microbiol 2000;38:669-76.

21. Diaz R, Kremer K, de Haas PE, Gomez RI, Marrero A, Valdivia JA, et al. Molecular epidemiology of tuberculosis in Cuba outside of Havana, July 1994-June 1995: utility of spoligotyping versus IS6110 restriction fragment length polymorphism. Int J Tuberc Lung Dis 1998;2:743-50.

22. Sola C, Devallois A, Horgen L, Maisetti J, Filliol I, Legrand E, et al. Tuberculosis in the Caribbean: using spacer oligonucleotide typing to understand strain origin and transmission. Emerg Infect Dis 1999;5:404 14.

23. Park YK, Bai GH, Kim SJ. Restriction fragment length polymorphism analysis of Mycobacterium tuberculosis isolated from countries in the western pacific region. J Clin Microbiol 2000;38:191-7.

24. Palittapongarnpim P, Luangsook P, Tansuphaswadikul S, Chuchottaworn C, Prachaktam R, Sathapatayavongs B. Restriction fragment length polymorphism study of Mycobacterium tuberculosis in Thailand using IS6110 as probe. Int J Tuberc Lung Dis 1997;1:370-6.

25. Dale JW, Nor RM, Ramayah S, Tang TH, Zainuddin ZF. Molecular epidemiology of tuberculosis in Malaysia. J Clin Microbiol 1999;37:1265-8.

26. van Rie A, Warren RM, Beyers N, Gie RP, Classen CN, Richardson M, et al. Transmission of a multidrug-resistant Mycobacterium tuberculosis strain resembling "strain W" among noninstitutionalized, human immunodeficiency virus-seronegative patients. J Infect Dis 1999;180:1608-15.

27. Tornieporth NG, Ptachewich Y, Poltoratskaia N, Ravi BS, Katapadi M, Berger JJ, et al. Tuberculosis among foreign-born persons in New York City, 1992-1994: implications for tuberculosis control. Int J Tuberc Lung Dis 1997;1:528-35.

Synopses. Articles should be approximately 3,500 words and should include references, not to exceed 40 . Use of subheadings in the main body of the text is recommended. Photographs and illustrations are encouraged. Provide a short abstract (150 words) and a brief biographical sketch of first author-both authors if only two.

This section comprises concise reviews of infectious diseases or closely related topics. Preference is given to reviews of new and emerging diseases; however, timely updates of other diseases or topics are also welcome. If detailed methods are included, a separate section on experimental procedures should immediately follow the body of the text.
28. Barnes PF, Yang Z, Preston-Martin S, Pogoda JM, Jones BE, Otaya M, et al. Patterns of tuberculosis transmission in Central Los Angeles. JAMA 1997;278:1159-63.

29. Yang Z, Barnes PF, Chaves F, Eisenach KD, Weis SE, Bates JH, Cave MD. Diversity of DNA fingerprints of Mycobacterium tuberculosis isolates in the United States. J Clin Microbiol 1998;36:1003-7.

30. Laserson KF, Osorio L, Sheppard JD, Hernandez H, Benitez AM, Brim S, et al. Clinical and programmatic mismanagement rather than community outbreak as the cause of chronic, drug-resistant tuberculosis in Buenaventura, Colombia, 1998. Int J Tuberc Lung Dis 2000;4:673-83.

31. Friedman CR, Stoeckle MY, Kreiswirth BN, Johnson WD Jr, Manoach SM, Berger J, et al. Transmission of multidrug-resistant tuberculosis in a large urban setting. Am J Respir Crit Care Med 1995;152:355-9.

32. Moss AR, Alland D, Telzak E, Hewlett D Jr, Sharp V, Chiliade P, et al. A city-wide outbreak of a multiple-drug-resistant strain of Mycobacterium tuberculosis in New York. Int J Tuberc Lung Dis 1997;1:115-21.

33. Le TK, Bach KH, Ho ML, Le NV, Nguyen TN, Chevrier D, et al. Molecular fingerprinting of Mycobacterium tuberculosis strains isolated in Vietnam using IS6110 as probe. Tuber Lung Dis 2000;80:75-83.

34. Torrea G, Levee G, Grimont P, Martin C, Chanteau S, Gicquel B. Chromosomal DNA fingerprinting analysis using the insertion sequence IS6110 and the repetitive element DR as strain-specific markers for epidemiological study of tuberculosis in French Polynesia. J Clin Microbiol 1995;33:1899-904.

35. Sola C, Filliol I, Gutierrez MC, Mokrousov I, Vincent V, Rastogi N. Spoligotype database of Mycobacterium tuberculosis: biogeographic distribution of shared types and epidemiologic and phylogenetic perspectives. Emerg Infect Dis 2001,7:390-6.

36. Bishai W. Tuberculosis transmission - rogue pathogen or rogue patient? Am J Respir Crit Care Med 2001;164:1104-5.

Address for correspondence: Judith Glynn, Department of Infectious and Tropical Diseases, London School of Hygiene and Tropical Medicine, Keppel Street, London WC1E 7HT, UK; fax: 44-(0)20-7636-8739; e-mail: judith.glynn@1shtm.ac.uk

\section{Upcoming in}

EMERGING

INFECTIOUS DISEASES

A Peer-Reviewed Journal Tracking and Analyzing Disease Trends

\section{Special Tuberculosis Theme Issue}

